\title{
Prevalence and Diffusion of Gastrointestinal Parasite Infections in Swamp Water Buffalo (Bubalus Bubalis) Populations from Marshlands of Iraq
}

\author{
Azmi Al-Jubury 1,*, Basim A. Jarullah², Khawla B.N. Al-Jassim³, Methaq Badran ${ }^{4}$ and \\ Yasser S. Mahmmod ${ }^{5,6}$
}

${ }^{1}$ Department of Veterinary and Animal Sciences, Faculty of Health and Medical Sciences, University of Copenhagen, 1870 Frederiksberg C, Denmark

${ }^{2}$ Department of Microbiology, Faculty of Veterinary Medicine, University of Thi-Qar, Thi-Qar Province, Iraq

${ }^{3}$ Central Animal Laboratory of Basra, Veterinary Hospital, Basra 61004, Basra Province, Iraq

${ }^{4}$ KPRRM limited, 71-75 Shelton Street, London, Greater London, WC2H 9JQ, UK

${ }^{5}$ Centre de Recerca en Sanitat Animal (CReSA-IRTA), Campus de la Universitat Autònoma de Barcelona, 08193-Bellaterra, Cerdanyola del Vallès, Barcelona, Spain

${ }^{6}$ Infectious Diseases, Department of Animal Medicine, Faculty of Veterinary Medicine, Zagazig University, Zagazig City, Sharkia Province 44511, Egypt

\begin{abstract}
Background and objectives: New information on the epidemiology of gastrointestinal (GI) parasite infection in water buffaloes is crucial for understanding their risk factors and transmission. The objectives of this study were (1) to determine the prevalence of GI parasites in buffaloes in the Marshland areas of southern Iraq, and (2) to evaluate the association of risk factors with the parasitic infections.

Materials and Methods: A total of 166 water buffaloes from the Marshland in the north of Basra $(n=75)$, and Thi-Qar $(n=91)$ provinces from November 2016 to April 2017 were enrolled. Fecal samples were collected and examined for the presence of helminth eggs and protozoal oocysts using sedimentation-flotation and centrifugal flotation techniques.

Results: The overall prevalence of infection in buffaloes was $82 \%(136 / 166)$, with the highest number of single parasite infection $(64 \%)$, followed by those with double $(29 \%)$ and triple $(7 \%)$ parasite infections. The most frequently identified parasites were Fasciola spp. $(23 \%, 39 / 166)$, Eimeria spp. $(19 \%, 32 / 166)$, Toxocara vitulorum $(13 \%, 21 / 166)$, Trichostrongylus spp. (12\%, 20/166), and Oesophagostomum spp. (10\%, 10/166). Moniezia spp. was the only identified cestode with a prevalence of $(8 \%, 13 / 166)$. A significant association was reported between feeding type and parasitic infections with Eimeria spp., Trichostrongylus spp., Moniezia spp., Trichuris spp., and Ostertagia ostertagia.

Conclusion: The prevalence of GI parasitic infection in buffaloes raised in the Marshlands is high, indicating a high intensity of natural infection. The findings of this study imply an urgent need for the implementation of efficient control measures against parasitic infections in the Marshlands.
\end{abstract}

Keywords: Swamp buffaloes, epidemiology, endoparasites, gastrointestinal parasites, Bubalus bubalis, Marshes.

\section{INTRODUCTION}

Large ruminants are important for livestock production systems. There are approximately 170 million water buffaloes worldwide. A majority of the water buffalo population is present in Asia, followed by Africa, South America, and Southern Europe [1]. Buffaloes are an essential part of the economy in many countries and provide sustainable food in addition to being working animals [2]. In some areas of southern Iraq, buffalo (Bubalus bubalis) is one of the most important domestic livestock species as it is a source of dairy and meat for the local population, as well as manure for the Marsh meadows [3]. With a total

*Address correspondence to this author at the Department of Veterinary and Animal Sciences, Faculty of Health and Medical Sciences, University of Copenhagen, 1870 Frederiksberg C, Denmark; Tel: +45 50528909;

E-mail: azmi@sund.ku.dk population of 40,000 , the majority of water buffaloes in Iraq are reared in the Marshes of three southern governorates Thi-Qar, Missan, and Basra [3].

Infectious diseases impact buffalo populations despite their adaptations to the local environment [4]. Infection by gastrointestinal $(\mathrm{Gl})$ parasites is one of the major problems, which can limit the livestock population and also adversely affect the health, fertility, and productivity of the animals [5-7]. The predominant factors affecting parasitic infections are grazing habits, climate, nutritional deficiency, pasture management, poor immunological status, presence of the vector/intermediate host, and the number of infective larvae and eggs in the environment [8]. Studying the parasite fauna of the water buffaloes allows determination of environmental factors on the course of 
parasitic infection, which is necessary for developing an appropriate control program [9-11].

The Marshlands in southern Iraq harbour the largest population of water buffaloes. UNESCO has named these Marshlands as a world heritage site because of its unique ecosystem, and its role as a major refuge for biodiversity [12]. The hot and humid climate in the Marshlands provides highly favourable conditions for the growth of parasites and their intermediate hosts. As a swamp animal, water buffalo spends most of its time swimming and grazing on the natural wetland vegetation. This behaviour likely increases their exposure to parasitic infections, as the intermediate hosts of fluke such as Fasciola hepatica (e.g., snails) are also abundant in such area. The occurrence of fascioliasis is strongly linked to the freshwater mollusc of the genus Lymnaea spp., which acts as an intermediate host of the liver fluke [13]. The diagnosis of fasciolosis is usually based on the detection of $F$. hepatica eggs in faeces or $F$. hepatica specific antibodies in serum. Studying the epidemiological determinants of liver fluke infections is important for improving the control program. That can be achieved by gathering information on the prevalence of the Fasciola spp. and potential risk factors associated with the spread of fascioliasis among the animals. The climate changes and direct human intervention have led to drastic changes in the Iraqi Marshes, including the desiccation of Marshes, lakes and other water bodies in the late $20^{\text {th }}$ century. Such changes in the natural environment of agriculture animals, particularly water buffaloes, may be associated with unfavourable and unpredictable consequences. In 2003, a sizeable ecological restoration project on the Marshes was initiated and had had remarkable success [14,15]. Furthermore, changes in the environment and management practices could influence the epidemiology and prevalence of the parasites $[16,17]$.

To the best of our knowledge, there is no available literature on the prevalence and epidemiology of $\mathrm{Gl}$ parasites among the water buffaloes in southern Iraq. Moreover, the available studies on GI parasites are somewhat outdated and inconclusive $[18,19]$. Thus, the present study aimed to provide a better understanding of GI parasite infections in water buffaloes following reflooding and restoration of the Mesopotamian Marshlands. The objectives of this study were (1) to determine the prevalence of helminths and the protozoa in the $\mathrm{Gl}$ of water buffalo population in Basra and Thi-Qar provinces, and (2) to identify the association of risk factors (age, location, gender, and feeding system type) with the parasitic infections. This might be the first report on the prevalence and epidemiology of $\mathrm{GI}$ parasites in water buffaloes in the southern region of Iraq. The findings of this study would provide an updated and exhaustive database for monitoring the ruminant health and propose appropriate, effective strategies for the treatment and control of parasitic infections.

\section{MATERIALS AND METHODS}

\section{Study Area}

The investigation was conducted in the Marshes of two southern provinces of Iraq (Basra and Thi-Qar). The first site (S1) is a part of the Marshes north of Basra, about $550 \mathrm{~km}$ south of Baghdad. The second site (S2) is located south of Thi-Qar's Marshes, $450 \mathrm{~km}$ south of Baghdad. The majority of the buffalo populations, which are raised in a free open range system, dwell in these two sites. The sampling locations are illustrated in Figure 1.

\section{Study Population and Sample Collection}

This study was carried out from November 2016 to April 2017 on water buffaloes $(n=166)$ from the north of Basra $(n=75)$ and Thi-Qar $(n=91)$ provinces. The farmers were considered for this study based on the criteria of being household breeders of water buffaloes with small-scale production system ( $<15$ animals), and their willingness to participate in the study after getting an overview about the study description and its objectives. Animals were selected randomly based on species (water buffaloes), being belonging to household breeders, and raised close to and/or grazed on the Marshes. The feeding system ranged from grazing only on the natural pastures and vegetation of the Marshes to a mixture of grazing and concentrated ration. Exclusion criteria were applied when the buffaloes are raised far away from Marshland, farmers hold a large production system or raising different animal species with the buffaloes. Additionally, animals received anthelmintic therapy at the time of sample collection were also excluded.

For parasite diagnosis, fresh faecal samples were collected per rectum using sterile plastic gloves. The samples were placed in leak-proof plastic containers, labelled, and transported to the Central Animal Laboratory of Basra. The details about animal characteristics including age, gender, and type of feeding system were obtained from the owner, while 


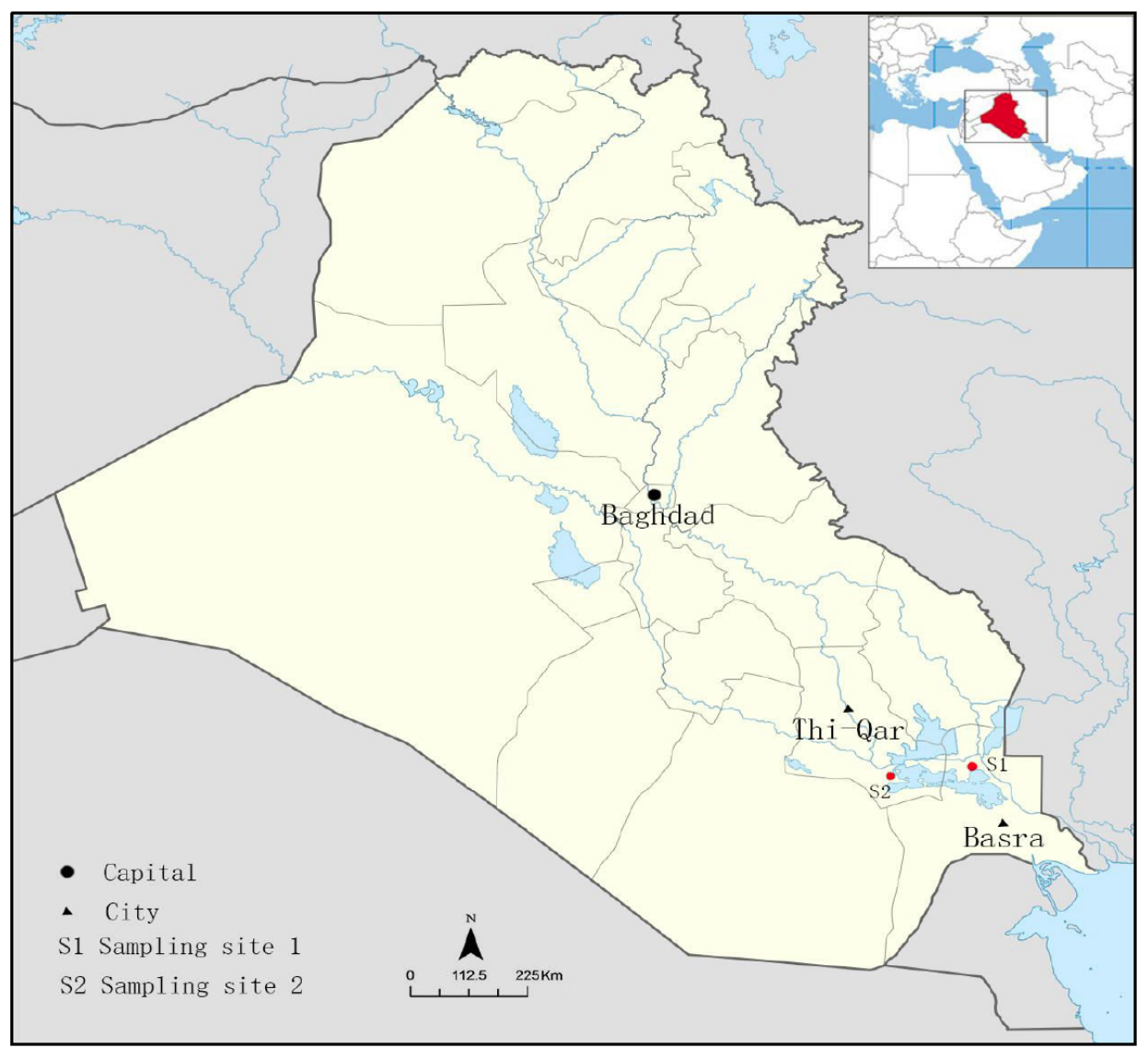

Figure 1: Study location showing the sampling sites at the Marshes of Mesopotamia land in Thi-Qar and Basra provinces, Iraq.

limited information was available on usage, frequency, and types of anthelmintic treatment. The faecal samples were examined in the laboratory for the presence of adult helminths and cestode proglottids using conventional macroscopic techniques. The faeces were then examined for helminths eggs, oocysts, and cysts through the sedimentation-flotation and centrifugal flotation technique using zinc chloride $[20,21]$. All protozoan cysts or oocysts and helminth forms were identified as per their morphological characteristics and the available guideline using light microscopy $[22,23]$. The results were expressed as the presence or absence of parasitic stages or parasites. A faecal sample was considered positive if at least one parasitic form was observed.

\section{Data Analysis}

The water buffaloes considered in this study belonged to two different geographical locations in southern Iraq: Thi-Qar, and Basra. The Buffaloes were classified as per their age ( $\leq$ one year, and $>$ one year) and gender. The available feed type for the buffaloes was also identified as grazing Marshes, a mixture of reeds, papyrus and concentrates, and only reeds and papyrus. The characteristics of the study population are described in (Table 1).

The overall prevalence was defined as the percentage of faecal samples positive for any parasitic species, and the specific prevalence was defined as the percentage of faecal samples positive for a specific parasite. For each parasite, the frequency of positive animals and the respective binomial 95\% confidence intervals were calculated. The association between the frequency of positives of parasitic eggs for each parasite and the independent variables such as age, province, gender, and feed type were investigated using the chi-square test. All statistical analyses were performed using R v3.0.3 (R Core Team; http://www.Rproject.org). The significance for all statistical analyses was defined at a $p$-value $<0.05$.

\section{RESULTS}

In total, 17 household breeders were visited around the Marshland areas of southern Iraq. No animals were excluded from this study based on the pre-specified exclusion criteria. The prevalence of protozoan cysts or oocysts and different helminths in the buffaloes are 
Table 1: Description of 166 Water Buffaloes Raised Around the Marshland in Southern Iraq Examined for Gastrointestinal Parasite Infection during the Period from November 2016 to April 2017

\begin{tabular}{|c|c|c|}
\hline Variable & Level & Number (\%) \\
\hline \hline \multirow{2}{*}{ Province } & Thi-Qar & $91(54.8)$ \\
\cline { 2 - 3 } & Basra & $75(45.2)$ \\
\hline \multirow{2}{*}{ Gender } & Female & $136(81.9)$ \\
\cline { 2 - 3 } & Male & $30(18.1)$ \\
\hline \multirow{2}{*}{ Age } & sone year & $29(17.5)$ \\
\cline { 2 - 3 } & > one year & $137(82.5)$ \\
\cline { 2 - 3 } & grazing_marshes & $75(45.2)$ \\
\cline { 2 - 3 } & RP and conce * & $45(27.1)$ \\
\cline { 2 - 3 } & RP * & $46(27.7)$ \\
\hline
\end{tabular}

${ }^{*} \mathrm{RP}=$ Reeds and papyrus, Conce $=$ concentrate mixture.

Table 2: The Number and Prevalence (\%) of Gastrointestinal Parasites in 166 Water Buffaloes Raised Around the Marshland in Southern Iraq Examined during the Period from November 2016 to April 2017

\begin{tabular}{|c|c|c|c|}
\hline Parasite Species & No. of infected buffaloes & Prevalence (\%) & 95\% Cl [\%] \\
\hline \hline Eimeria spp & 32 & 19 & $14-26$ \\
\hline Fasciola spp & 39 & 23 & $8-30$ \\
\hline Trichostrongylus spp & 20 & 12 & $5-13$ \\
\hline Haemonchus contortus & 14 & 8 & $6-16$ \\
\hline Oesophagostomum spp & 17 & 10 & $6-16$ \\
\hline Ostertagia ostertagi & 17 & 10 & $4-12$ \\
\hline Strongyloides spp & 12 & 7 & $8-19$ \\
\hline Toxocara vitulorum & 21 & 6 & $3-11$ \\
\hline Trichuris spp & 11 & 8 & $5-13$ \\
\hline Moniezia spp & 13 & 100 & - \\
\hline Total & 196 & & \\
\hline
\end{tabular}

${ }^{*}$ Total is higher than 136 because some of the examined animals were infected by multiple parasites (Multiple parasitisms).

Table 3: The Number of Single and Multiple Infections for each Parasite in 166 Water Buffaloes Raised Around the Marshland in Southern Iraq Examined during the Period from November 2016 to April 2017

\begin{tabular}{|c|c|c|c|c|}
\hline \multirow{2}{*}{ Parasite species } & \multicolumn{3}{|c|}{ The number of parasite species in infected buffaloes } & \multirow{2}{*}{ Tota } \\
\hline & Single & Double & Triple & \\
\hline Eimeria spp & 11 & 15 & 6 & 32 \\
\hline Fasciola spp & 20 & 12 & 7 & 39 \\
\hline Haemonchus contortus & 4 & 6 & 4 & 14 \\
\hline Oesophagostomum spp & 8 & 5 & 4 & 17 \\
\hline Strongyloides spp & 6 & 4 & 2 & 12 \\
\hline Toxocara vitulorum & 12 & 8 & 1 & 21 \\
\hline Trichostrongylus spp & 9 & 8 & 3 & 20 \\
\hline Trichuris spp & 5 & 6 & 0 & 11 \\
\hline
\end{tabular}

${ }^{*}$ Total is higher than 136 because some of the examined animals were infected by multiple parasites (Multiple parasitisms). 
presented in Tables 2 and $\mathbf{3}$. The overall prevalence of GI parasitic infection was $82 \%(136 / 166)$. Ten genera of intestinal parasites were detected, and helminths were more prevalent than protozoan parasites (Table 2). Different types of helminths were identified, including seven nematodes, one cestode, and one trematode. The most frequently observed parasites in this study were Fasciola spp. (23\%; 39/166) followed by Eimeria spp. (19\%; 32/166), Toxocara spp. (13\%; 21/166), and Trichostrongylus spp. (12\%; 20/166). The only intestinal protozoan parasite identified as Eimeria spp. at $19 \%(32 / 166)$ prevalence, whereas the only cestode parasite identified was Moniezia spp. at $8 \%$ (13/166) prevalence (Table 3).

The infections with single parasite species were more frequent $(64 \%, 87 / 136)$ than those with double $(29 \%, 39 / 136)$ and triple $(7 \%, 10 / 136)$ parasite species (Table 4). Buffaloes over the age of one year had a higher overall parasitic prevalence $(66 \% ; 110 / 166)$ than those that were less than one year of age $(16 \%$; 24/166). The female buffaloes had a higher overall prevalence of infections $(66 \% ; 110 / 166)$ than males (16\%; 26/166), (Table 4). The buffaloes that grazed in Marshes had a higher overall prevalence of infections $(34 \% ; 56 / 166)$ than those that fed on a mixture of reeds, papyrus and concentrates (24\%; 39/166), and reeds and papyrus only $(25 \% ; 41 / 166)$. Likewise, the buffaloes from Thi-Qar province (48\%; 80/166) had a higher overall prevalence of parasitic infections than those from Basra (34\%; 56/166), (Table 4).

The associations between the presence of a parasite and gender, province, feeding type, and age $(P<0.05)$ are listed in Table 5. A significant association was reported between feed type and parasitic infections with Eimeria spp. (P-value < 0.05), Trichostrongylus spp. (P-value < 0.05), Moniezia spp. (P-value < 0.05), Trichuris spp. (P-value < 0.01), and Ostertagia ostertagi (P-value $<0.001)$. Buffaloes that grazed on the Marshlands were more susceptible to parasitic infections with Eimeria spp., Trichostrongylus spp., and Moniezia spp. than those that fed on the mixture of reeds, papyrus and concentrates, and reeds and papyrus only. No significant association was reported between the buffalo age and parasitic infections except for Toxocara spp. Water buffaloes with less than one year have a higher susceptibility to Toxocara spp. (P-value < 0.001). A significant association was reported between the location of the sampled buffaloes and parasitic infections. Thus, buffaloes from Thi-Qar province were more susceptible to parasitic infections with Ostertagia ostertagi ( $\mathrm{P}$-value $<0.001$ ), Strongyloides spp. (P-value $<0.05$ ), and Trichuris spp. (P-value $<0.001)$ than those from Basra province, while those from Basra were more susceptible to Moniezia spp. (P-value < 0.05) infection. No significant association was found between the type of $\mathrm{Gl}$ parasites and gender of buffaloes.

\section{DISCUSSION}

As per the literature and our best knowledge, this is the first systematic investigation of the prevalence of $\mathrm{GI}$ parasites in the Marshlands at southern Iraq, (Basra and Thi-Qar provinces) after the geographical changes in the Marshes area. During the study period from November 2016 to April 2017, a high proportion of animals were recorded positive (82\%) for $\mathrm{Gl}$ infections, showing the susceptibility of buffaloes to the different GI parasites infections. Several earlier studies from different countries and geographical regions including Asia [7,24,25], Africa [26], Europe [9-11], and South America [27], have reported wide variations in the parasitic intestinal infections among buffaloes.

The high prevalence of $\mathrm{GI}$ parasites detected in this study is in agreement with earlier reports at $91.44 \%$ [28] and 92.73\% [29]. Correspondingly, in Diyala province of Iraq, $85.0 \%$ prevalence rate of GI parasites in cattle was reported [30]. Later, El Damaty et al., (2018) observed that cattle have less chance of being infected with Fasciola spp. compared to water buffaloes [31] in Delta of Egypt. The high liability of water buffaloes to be infected with GI parasites may be attributed to factors such as the level of host immunity, and the stage of parasite infection. Other inherent Marsh-specific ecological factors include moisture, humidity, vegetation, soil, and animal interactions [32], in addition to long and frequent contact with the freshwater in the Marshes, and with snails, the intermediate host of the parasites. Mainly, the prevalence of parasitic infection observed in our current study is much higher than that in Basra province [33] and Mexican tropical conditions [34]. While the nematode prevalence in African buffalo was $70 \%$, it has also been reported in Poland at 44\% [9]. In earlier surveillance Italian study by Condoleo et al., (2007), the prevalence of helminths was varying from $33.1 \%$ for gastrointestinal strongyles to $2.4 \%$ for Moniezia spp.

This remarkable variation in the prevalence between the present study and the other studies can be attributed to several factors such as geographical location and the wet and cold environmental conditions 

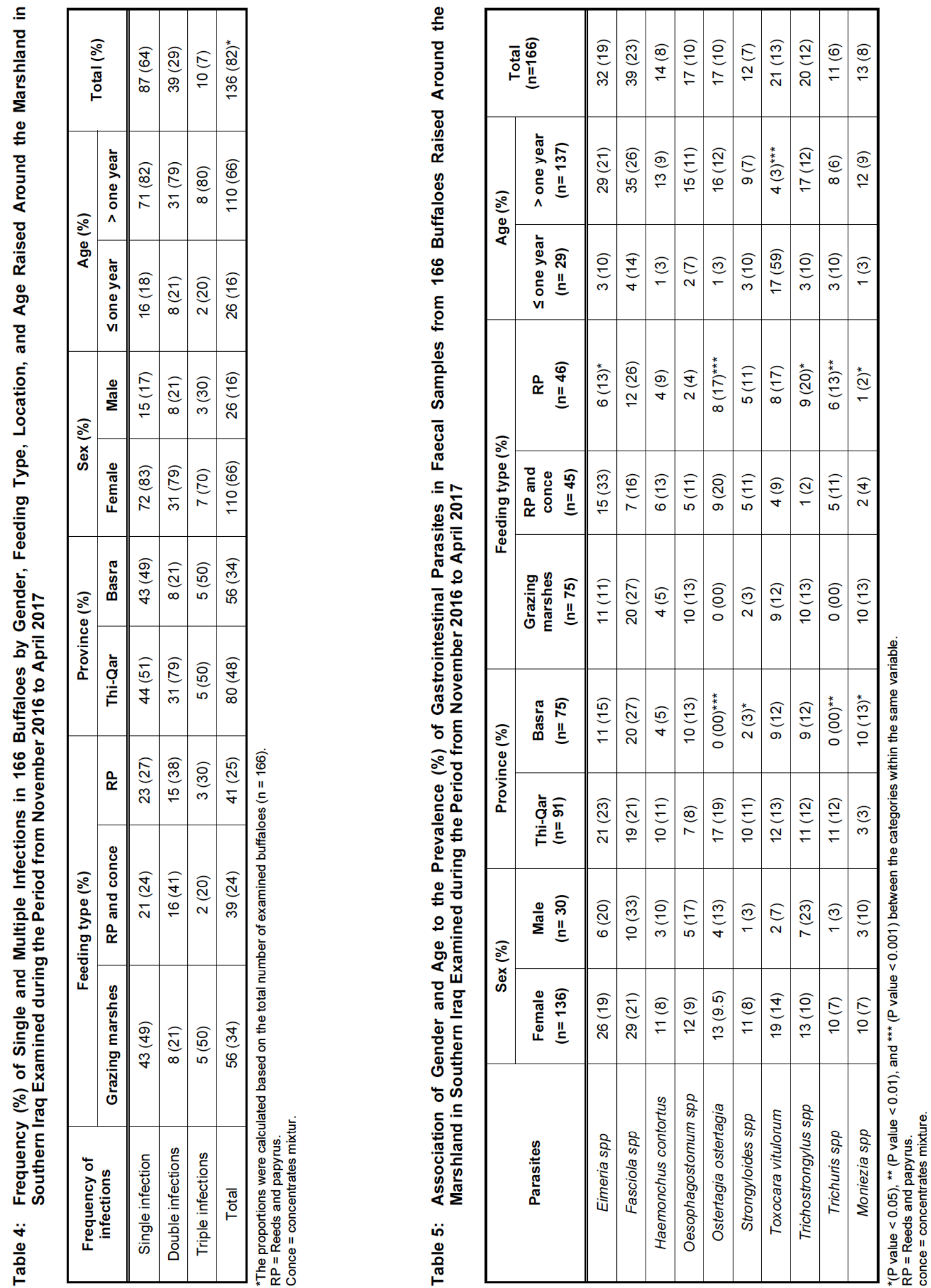
experienced during the study period. Parasitic outbreaks are more likely to occur under wet and humid conditions [35]. Likewise, the prevalence of $\mathrm{GI}$ parasite in cattle is much higher in March and April (springtime in Iraq) than in August (summertime) [33], which agrees with our findings. However, proper management and farming practices lead to low GI nematodes infection, as these are considered to be a serious concern in grazing animals [36]. Other factors may have an impact on the prevalence of the parasites, such as sampling procedures, socio-economic level, demographic factors, anthelmintic usage and frequency, deworming drugs, and diagnostic techniques employed. In our study, ten genera of intestinal parasites were identified. The only detected protozoan parasite was Eimeria spp. with a prevalence of $19 \%$. This is a relatively high prevalence comparable to an earlier report, where $40 \%$ prevalence was observed [29]. Among helminths, the most common was Fasciola spp. (23\%) followed by Toxocara spp. (13\%), and Trichostrongylus spp. (12\%). However, compared to our results, lower prevalence of parasites species was detected in cattle, including Ascaris spp. (7.96\%), Strongylus spp. (4.53\%), and Fasciola spp. (5.15\%), [37]. The present study appears to be the first one to report the presence of Fasciola spp. in water buffaloes in the Marshlands in Iraq. The high rate of infection is caused because of the lack of appropriate parasite control program. This is in agreement with $\mathrm{El}$ Damaty et al. 2018 [31], who found that administrating anthelmintic to animals on a regular basis decreased the risk of copro-positivity to Fasciola spp. by $0.17 \%$ in comparison to animals that received irregular doses of anthelmintic. Additionally, buffaloes are raised on marshy pastures with high humidity, which favours the growth and multiplication of parasites as well as their vectors [9].

This remarkable finding is in accordance with the findings of El Damaty et al., 2018 [31] who reported a high prevalence of fascioliasis $(33 \%)$ in water buffalo in Egypt. The authors attributed this high prevalence that water buffalo is a swamp animal prefer to frequently swim in the fresh Nile water, and therefore, it is frequently exposed to the intermediate host of Fasciola spp. parasite, where snails are commonly inhabited in the water channels, rivers and swamps [38]. This explanation is typically consistent with our case, where the ecological conditions at the Iraqi Marshes are similar to the environmental conditions in the Nile River. Thus, we believe that these conditions play is a major factor in the demonstrated high prevalence.
Kaplan, 2001 [39] added that buffaloes get infected via drinking contaminated water and/or ingesting the vegetation growing on the edges of the Marshes, which harbour the metacercaria cysts, infective stages of Fasciola spp.

We found that the overall prevalence of GI parasitic infection in adult buffaloes or those over one-year-old $(66 \%)$ is higher than those in young animals $(16 \%)$. While our finding is in accordance with some studies $[37,40]$, it is inconsistent with others [41,42], which report a higher prevalence of helminth infections in younger buffaloes. The cause of this variation based on age is challenging to explain, but it might be due to an exhausted immune system, or different grazing areas and management practices for the animals. Notably, our study showed that calves of water buffaloes less than one-year-old have a significantly higher susceptibility to Toxocara spp. infections than adult buffaloes. This is an agreement with previous studies, which demonstrated that bovid calves tend to be the only age group from which the Toxocara parasite's eggs are shed [43-46], where these young animals ingest larvae found in the colostrum and milk from infected cows [44].

Furthermore, a gender-related prevalence of gastrointestinal parasites was observed in buffaloes; females were more susceptible $(77.1 \%)$ to GI parasitic infection than males (16.9\%). Despite we did not found a statistical significance but our findings also support a previous study in which a higher prevalence of helminths in female buffalo calves $(66 \%)$ than in males (16\%) was reported [47], while Maqbool et al., 2002 [48] reported no gender-based variation in GI parasitic infection of the host. The higher percentage of infection in the females may be due to physiological stress conditions during pregnancy and lactation. Additionally, a higher level of prolactin and progesterone hormones make the female more susceptible to gastrointestinal parasites [49].

In the present investigation, single-infections were more common (64\%) than double infections (29\%), whereas the prevalence of infection with triple parasite species was only $7 \%$, which is in agreement with an earlier findings that reported $47 \%$ and $9 \%$ double and triple parasitic infections, respectively [50]. Nevertheless, other previous studies showed mixed infection with one or more helminths [37] and a much higher percentage of double infection than single infection, which contradicts our observations [29]. This variation in a number of parasitic infections per animal 
could be attributed to the differences in the feeding system, localities, climate conditions, and environmental factors in addition to the animal individual genetic and immune variations. We postulate that the multiple parasitisms observed in our study may be due to limited veterinary care program, which increases the risk of disease transmission among water buffalo populations.

Our study demonstrates that feeding type has a significant effect on the occurrence of infection; thus, free grazing type buffaloes at Marshes were more susceptible and had a higher overall prevalence of infections than the other feeding types. A plausible explanation for this may be the water wallowing habit of buffaloes in the marshy area, which provide a suitable environment for most of the parasites and their intermediate hosts to grow and propagate [39]. Our finding is entirely in agreement with that of another report [51], which indicated that outdoor animal rearing results in heavier, or more prevalent helminth infections compared to intensive rearing in indoor conditions.

Buffaloes from Thi-Qar's Marshes had a higher overall prevalence of infections (48\%) than those from Basra $(34 \%)$. The environmental conditions that the buffaloes were exposed to, particularly the Marshes of these two locations, were similar. However, compared to the Basra region, the Thi-Qar region has a larger Marsh area and the countryside is connected more to the rural and animal farmers. Additionally, the population density of buffaloes and other livestock species, as well as the variations in the management practices and veterinary services, may have some influence on the overall prevalence of different parasitic infections in the area. Our findings may provide a basis for assessing the effectiveness of future control strategies against parasitic infections in water buffalo populations and also assist in the implementation of these measures in the Marshland areas of southern Iraq.

\section{CONCLUSIONS}

We report a high prevalence of parasitic gastrointestinal infection in water buffaloes raised in the Marshlands area in southern Iraq, suggesting the need for an effective control measure under this common type of production system. The most frequently detected parasites were Fasciola spp., Eimeria spp., Toxocara spp., Trichostrongylus spp., and Oesophagostomum spp. Specific guidelines for strategic parasitic control in the Marshland area are crucial for improving the health and productive efficiency of buffaloes in this area. Further epidemiological studies are warranted to monitor the prevalence of GI parasites in water buffaloes.

\section{ACKNOWLEDGEMENTS}

We thank the veterinarians and staff members of veterinary clinics in Basra and Thi-Qar for their assistance in obtaining and processing faecal samples. Special thanks to Leah Lourenco for providing suggestions and help in preparing the manuscript. We would also like to thank the anonymous buffalo owners for providing us with the data on their animals. The authors would like to acknowledge Ahmed Mahmood Badran for his help and technical assistance.

\section{COMPLIANCE WITH ETHICAL STANDARDS}

\section{Conflict of Interest}

The authors declare no conflict of interest. No competing financial interests exist.

\section{REFERENCES}

[1] Wanapat M, Chanthakhoun V. Buffalo Production for Emerging Market as a Potential Animal Protein Source for Global Population. Buffalo Bull 2015; 34: 169-180.

[2] Abu Tabeekh MAS, Abdul Abdul Mohsen HA, Al Jaberi AA The Reality of Buffalo Breeding in Basra Governorate. J Buffalo Sci 2017; 6: 8-18.

https://doi.org/10.6000/1927-520X.2017.06.01.2

[3] Abid HS, Fazaa NA. Water Buffalo in the Iraqi Marshes. In Nature Iraq Status Report 2007. Sulaimani, Kurdistan, Iraq. (Accessed in 10 October 2019). http://www.natureiraq.org/ uploads/9/2/7/0/9270858/status_report_buffalothiqar.pdf

[4] Guccione J, Perreten V, Steiner A, Thomann A, Pesce A, Ciaramella P, Bodmer M. Short communication: Role of Streptococcus pluranimalium in Mediterranean buffaloes (Bubalus bubalis) with different udder health statuses. J Dairy Sci 2016; 99: 2945-2949.

https://doi.org/10.3168/jds.2015-10291

[5] Vercruysse J, Claerebout E. Treatment vs non-treatment of helminth infections in cattle: defining the threshold. Vet Parasitol 2001; 98: 195-214. https://doi.org/10.1016/S0304-4017(01)00431-9

[6] Hoste H, Torres-Acosta JF, Aguilar-Caballero AJ. Nutritionparasite interactions in goats: is immunoregulation involved in the control of gastrointestinal nematodes? Parasite Immunol 2008; 30: 79-88.

[7] Pandya SS, Hasnani JJ, Patel PV, Chauhan VD, Hirani ND, Shukla R, Dhamsaniya HB. Study on prevalence of Fasciolosis in buffaloes at Anand and Ahmedabad districts, Gujarat, India. Vet World 2015; 8: 870-874. https://doi.org/10.14202/vetworld.2015.870-874

[8] Sargison ND. Keys to solving health problems in small ruminants: Anthelmintic resistance as a threat to sustainable nematode control. Small Ruminant Res 2016; 142: 11-15. https://doi.org/10.1016/..smallrumres.2016.02.021

[9] Kobak P, Pilarczyk B. Prevalence of Gastrointestinal Parasites of Water Buffaloes Raised in the Notecka Forest Region (Poland). B Vet I Pulawy 2012; 56: 33-36. https://doi.org/10.2478/v10213-012-0006-4 
[10] Salvador RT, Abalos RP, Ruba AM, Mingala CN. A comparison of FLOTAC and CFF techniques in detecting gastrointestinal parasites in water buffaloes (Bubalus bubalis). Ann Parasitol 2014; 60: 119-125.

[11] Condoleo RU, Veneziano V, Bruni G, Santaniello $M$, Carbone S, Pennacchio S, Rinaldi L, Cringoli C. Distribution of helminthes in buffalo farms from central Italy. Ital J Anim Sci 2007; 6: 920-922. https://doi.org/10.4081/ijas.2007.s2.920

[12] Garstecki T, Amr Z. Biodiversity and Ecosystem Management in the Iraqi Marshlands -Screening Study on Potential World Heritage Nomination (Amman, Jordan: IUCN) 2011; pp. 190. https://whc.unesco.org/en/decisions/6794/ (Accessed $2^{\text {nd }}$ October 2019).

[13] Sharma RL, Godara R, Thilagar MB. Epizootiology, pathogenesis and im-munoprophylactic trends to control tropical bubaline fasciolosis: an overview. J Parasit Dis 2011; 35: 1-9.

https://doi.org/10.1007/s12639-011-0025-8

[14] Richardson CJ, Reiss PR, Hussain NA, Alwash AJ, Pool DJ. The Restoration Potential of the Mesopotamian Marshes of Iraq 2005; pp. 1307-1311. https://doi.org/10.1126/science. 1105750

[15] Salim MA, Abd IM, Abdulhassan NA, Minjal MS. Key Biodiversity Survey of Southern Iraq (Sulaimani, Kurdistan, Iraq) 2009; pp. 121.

[16] Knubben-Schweizer G, Rüegg S, Torgerson PR, Rapsch C, Grimm F, Hässig M, Deplazes P, Braun U. Control of bovine fasciolosis in dairy cattle in Switzerland with emphasis on pasture management. Vet J 2010; 186: 188-191. https://doi.org/10.1016/j.tvjl.2009.08.003

[17] Knubben-Schweizera G, Torgersonb PR. Bovine fasciolosis: Control strategies based on the location of Galba truncatula habitats on farms. Vet Parasitol 2015; 208: 77-83. https://doi.org/10.1016/j.vetpar.2014.12.019

[18] Kurtpinar $\mathrm{H}$, Lafit BM. Paramphistomiasis of cattle and buffaloes in Iraq. Vet Record 1970; 87: 668. https://doi.org/10.1136/vr.87.21.668-a

[19] Al-ttai, LHK. A survey of parasites in buffaloes with a study of the intermediate host of Gigantocotyle explanatum (in Iraq). University of Baghdad. PhD thesis 1983. http://agris.fao.org/ agris-search/search.do?recordID=IQ8500191 (Accessed in 10 October 2019).

[20] Zajac AM, Conboy G. Veterinary clinical parasitology. Blackwell Publishing, lowa, 2006; pp. 368

[21] Charlier J, De Meulemeester L, Claerebout E, Williams D, Vercruysse J. Qualitative and quantitative evaluation of coprological and serological techniques for the diagnosis of fasciolosis in cattle. Vet Parasitol 2008; 153: 44-51. https://doi.org/10.1016/j.vetpar.2008.01.035

[22] Soulsby EJL. Helminths, Arthropod and Protozoa of Domesticated Animals, $7^{\text {th }}$ ed. 1982; pp. 35-740.

[23] Bowman DD, Lynn RC, Eberhard ML, Georgi JR. Georgis' parasitology for veterinarians 2003; 496.

[24] Liu Y, Li F, Liu W, Dai RS, Tan YM, He DS, Lin RQ, Zhu XQ. Prevalence of helminths in water buffaloes in Hunan Province, China. Trop Anim Health Prod 2008; 41: 543-546. https://doi.org/10.1007/s11250-008-9219-1

[25] Mamun MAA, Begum N, Shahadat HM, Mondal MMH. Ectoparasites of buffaloes (Bubalus bubalis) in Kurigram district of Bangladesh. J Bangladesh Agric Univ 2010; 8: 6166. https://doi.org/10.3329/jbau.v8i1.6400

[26] Gorsich EE, Ezenwa VO, Jolles AE. Nematode-coccidia parasite co-infections in African buffalo: Epidemiology and associations with host condition and pregnancy. Int $\mathrm{J}$ Parasitol Parasites Wild 2014; 3: 124-134. https://doi.org/10.1016/j.ijppaw.2014.05.003
[27] Bethencourt AM, Quijada JJ, Cabrera P, Aguirre AM, García ME, Sulbarán DC, Vivas EH. Prevalencia y Abundancia de Huevos de Estróngilos Digestivos y Ooquistes de Eimeria spp. en Búfalos de Agua Infectados Naturalmente. Parasitología 2013; 54: 17-28.

[28] Rehman K, Javed K, Tunio MT, Kuthu ZH. Passive Sulveillance of Gastrointestinal Parasites in Buffaloes of Mandi Bahauddin and Gujrat Districts of the Punjab. J Anim Plant Sci 2009; 19: 17-19.

[29] Founta A, Papadopoulos E, Chliounakis S, Bampidis VA, Papazahariadou M. Presence of endoparasites in the Greek buffalo (Bubalus bubalis) from Northern Greece. J Hell Vet Med Soc 2018; 69(2): 999-1003. https://doi.org/10.12681/jhvms.18019

[30] Minnat TR, Alzubaidei HHH, Al-Ezzy AIA. Heamatological Changes Associated with Gastrointestinal Parasites Infection in Domestic Animals attended to Outpatient Clinic of Faculty of Veterinary Medicine of Diyala University, Iraq. Int J Inno Appl stud 2014; 9: 1266-1274.

[31] El Damaty HM, Mahmmod YS, Goudad SM, Sobhya NM. Epidemiological and ultrasonographic investigation of bovine fascioliasis in smallholder production system in Eastern Nile Delta of Egypt. Prev Vet Med 2018; 158: 35-42. https://doi.org/10.1016/j.prevetmed.2018.07.009

[32] Gunathilaka N, Niroshana D, Amarasinghe D, Udayanga L. Prevalence of Gastrointestinal Parasitic Infections and Assessment of Deworming Program among Cattle and Buffaloes in Gampaha District, Sri Lanka. Biomed Res Int 2018; 2018: 3048373. https://doi.org/10.1155/2018/3048373

[33] Al-Azizz S, Thamer NK, Jwad ZM, Aiad, M. A Survey of gastrointestinal parasites from slaughtered animals at Basrah abattoir. Al-Qadisyah J Pure Sci 2008; 13(4): 1-5.

[34] Ojeda-Robertos NF, Torres-Chable OM, Peralta-Torres JA, Luna-Palomera C, Aguilar-Cabrales A, Chay-Canul AJ, Gonzalez-Garduno R, Machain-Williams C, CamaraSarmiento R. Study of gastrointestinal parasites in water buffalo (Bubalus bubalis) reared under Mexican humid tropical conditions. Trop Anim Health Prod 2017; 49(3): 613618.

https://doi.org/10.1007/s11250-017-1237-4

[35] Radostits OM, Gay CC, Hinchcliff KW. Nematodes in animals. In: Text book of the disease of cattle, horse, sheep, pigs and goats $10^{\text {th }} \mathrm{Ed}, 2007 ;$ p. 2065.

[36] Sanchez J, Dohoo I, Carrier J, DesCôteaux L. A metaanalysis of the milk-production response after anthelmintic treatment in naturally infected adult dairy cows. Prev Vet Med 2004; 63: 237-256. https://doi.org/10.1016/j.prevetmed.2004.01.006

[37] Yadav A, Khajuria JK, Raina AK. Gastrointestinal parasitic infestation profile of bovines at RS Pura. J Vet Parasitol 2004; 18: 167-169

[38] de Kock KN, Wolmarans CT, Bornman M. Distribution and habitats of the snail Lymnaea truncatula, intermediate host of the liver fluke Fasciola hepatica, in South Africa. J S Afr Vet Assoc 2003; 74: 117-122. https://doi.org/10.4102/jsava.v74i4.523

[39] Kaplan RM. Fasciola hepatica: a review of the economic impact in cattle and considerations for control. Vet Ther 2001; 2: 40-50.

[40] Biswas H, Rani Dey A, Begum N, Mohan Das $P$ Epidemiological aspects of gastro intestinal parasites in buffalo in Bhola, Bangladesh. Indian J Anim Sci 2014; 84: 245-250.

[41] Mamun MAA, Begum N, Mondal MMH. A coprological survey of gastrointestinal parasites of water buffaloes (Bubalus bubalis) in Kurigram district of Bangladesh. J Bangladesh Agric Univ 2011; 9: 103-109.

https://doi.org/10.3329/jbau.v9i1.8752 
[42] Raza MA, Iqbal Z, Jabbar A, Yaseen M. Point prevalence of gastrointestinal helminthiasis in ruminants in southern Punjab, Pakistan. J Helminthol 2007; 81: 323-328. https://doi.org/10.1017/S0022149X07818554

[43] Woodbury MR, Copeland S, Wagner B, Fernando C, Hill JE, Clemence $\mathrm{C}$. Toxocara vitulorum in a bison (Bison bison) herd from western Canada. Can Vet J 2012; 53(7): 791-4.

[44] Woodbury MR, Wagner B, Ben-Ezra E, Douma D, Wilkins W. A survey to detect Toxocara vitulorum and other gastrointestinal parasites in bison (Bison bison) herds from Manitoba and Saskatchewan. Can Vet J 2014; 55(9): 870-4.

[45] Chelladurai JJ, Bader C, Snobl T, Magstadt D, Cooper V, Brewer MT. Toxocara vitulorum infection in a cohort of beef calves in lowa. Vet Parasitol 2015; 214(1-2): 96-99. https://doi.org/10.1016/j.vetpar.2015.10.004

[46] Venjakob PL, Thiele G, Clausen PH, Nijhof AM. Toxocara vitulorum infection in German beef cattle. Parasitol Res 2017; 116(3): 1085-1088. https://doi.org/10.1007/s00436-017-5393-2
[47] Bhutto B, Phullan MS, Rind R, Soomro AH. Prevalence of Gastrointestinal helminths in Buffalo calves. J Biol Sci 2002; 2: 43-45. https://doi.org/10.3923/jbs.2002.43.45

[48] Maqbool A, Hayat CS, Akhtar T, Hashmi HA. Epidemiology of fasciolosis in buffaloes under different managemental conditions. Vet Arh 2002; 72: 221-228.

[49] Lloyd S. Effect of pregnancy and lactation up on infection. Vet Immunol Immunopathol 1983; 4: 153-176. https://doi.org/10.1016/0165-2427(83)90057-0

[50] Agneessens J, Claerebout E, Dorny P, Borgsteede FHM, Vercruysse $\mathrm{J}$. Nematode parasitism in adult dairy cows in Belgium. Vet Parasitol 2000; 90: 83-92. https://doi.org/10.1016/S0304-4017(00)00232-6

[51] Thamsborg SM, Roepstorff A, Larsen M. Integrated and biological control of parasites in organic and conventional production systems. Vet Parasitol 1999; 84: 169-186. https://doi.org/10.1016/S0304-4017(99)00035-7

DOI: https://doi.org/10.6000/1927-520X.2020.09.06

(C) 2020 Al-Jubury et al.; Licensee Lifescience Global.

This is an open access article licensed under the terms of the Creative Commons Attribution Non-Commercial License (http://creativecommons.org/licenses/by-nc/3.0/) which permits unrestricted, non-commercial use, distribution and reproduction in any medium, provided the work is properly cited. 